\title{
Cognitive performance after strenuous physical exercise
}

Citation for published version (APA):

Hogervorst, E., Riedel, W. J., Jeukendrup, A. E., \& Jolles, J. (1996). Cognitive performance after strenuous physical exercise. Perceptual and Motor Skills, 83, 479-488.

https://doi.org/10.2466/pms.1996.83.2.479

Document status and date:

Published: 01/01/1996

DOI:

10.2466/pms.1996.83.2.479

Document Version:

Publisher's PDF, also known as Version of record

\section{Please check the document version of this publication:}

- A submitted manuscript is the version of the article upon submission and before peer-review. There can be important differences between the submitted version and the official published version of record.

People interested in the research are advised to contact the author for the final version of the publication, or visit the DOI to the publisher's website.

- The final author version and the galley proof are versions of the publication after peer review.

- The final published version features the final layout of the paper including the volume, issue and page numbers.

Link to publication

\footnotetext{
General rights rights.

- You may freely distribute the URL identifying the publication in the public portal. please follow below link for the End User Agreement:

www.umlib.nl/taverne-license

Take down policy

If you believe that this document breaches copyright please contact us at:

repository@maastrichtuniversity.nl

providing details and we will investigate your claim.
}

Copyright and moral rights for the publications made accessible in the public portal are retained by the authors and/or other copyright owners and it is a condition of accessing publications that users recognise and abide by the legal requirements associated with these

- Users may download and print one copy of any publication from the public portal for the purpose of private study or research.

- You may not further distribute the material or use it for any profit-making activity or commercial gain

If the publication is distributed under the terms of Article $25 \mathrm{fa}$ of the Dutch Copyright Act, indicated by the "Taverne" license above, 
Percepart and Motor Skils, 1996,83,479488. OPercepual and Motor Skills 1996

\section{COGNTTIV PERFORMANCE AFTER STRENUOUS PHYSICAL EXERCISE}

\section{EEF HOGERVORST, WTM REDEL ASKER JEUKENDRUP \\ Departmemt of Pychiaty and Nenopsychologs \\ Depantrent of Howan Biology}

JLLEJ JOLLES

Depaptwent of Probuthy and Noproprychalogy

University of Limburg, Marastrich

Summary - Stimulating as well as detrimental effects of exercise on cognitive functioning have been reported. In the present study, 15 endurance-trained athletes (aged 18 to 42 years) performed a bicycle ergometer endurance test at $75 \%$ of their maximal work capacity (W/max). Psychomoror and cognitive tests were administered before and immediately after exercisc. These consisted of simple reaction time (RT), 3-choice RT and Stimulus-Response (S-R) incompatible RT tasks, a finger-tapping task, and the Stroop test. Simple RT tasks, but also the more complex S-R in cornpatible RT, and Color Word Interference in the Stroop test showed an increase in speed of performance after exercise relative to baseline. An enhanced activation was probably responsible for this better performance on psychomotor and cognitive rests. Since performance on the most complex task, the Interference subtest of the Stroop, was especially improved after exercise, the expectancy of the subjects of a potential positive effect of exercise was thought to have been responsible.

Controversies exist over the effect of exercise on cognition. Several studies have described a negative effect of strenuous physical exercise on performance of cognitive tasks (Gutin, 1973; Isaacs \& Pohlman, 1991; Hancock \& McNaughton, 1986; McMorrís \& Keen, 1994; Salmela \& Ndoye, 1986$).$ Fatigue has often been hypothesized to underlie the negative influence of intense exercise on cognition (Tomporowski, Ellis, \& Stephens, 1987) but not all authors have found strenuous exercise had a negative effect on cognitive functions (Adam, Teeken, Ypelaar, \& Verstappen, in press; Bard \& Fleury, 1987; Côté, Salmela, \& Papathanasopoulu, 1992; Fleury, Bard, Jobin, \& Carriere, 1981; Pas \& Adam, 1991; Tomporowski, et al, 1987). The various results are difficult to compare. Some studies tested subjects from different backgrounds and with different levels of fitness, and various cognitive tasks were used either during or after exercise of varying duracions (McMorris \& Keen, 1994; Tomporowski \& Ellis, 1986). Often, exercise of a short duration (varying from 2 to $15 \mathrm{~min}$ ) was used and the amount of fatigue was not evaluated. Matters are further complicated since, as Tomporowski and Ellis (1986) stated, there is no agreement on the definition of farigue. According to Tatakuwa (1971), fatigue is defined as the combined out-

\footnotetext{
Please address enquiries to Eef Hogervorst, Deparment of Psychiatry and Neuropsychology, Universicy of Limburg, P.O. Box $616,6200 \mathrm{MD}$ Mastricht, The Nethetands or e-mail (e.hogervost NP. RuLimburg NL).
} 
put of mental activity and physiological functions. This definition was used by Hancock and McNaughton (1986), who found that fatiguing exercise (runing on a treadmill at or above the anaerobic threshold) inhibited especally higher mental skills such as decision-making. Isaacs and Pohlman (1991) also showed that exercise with a heavy workload (cycling at $100 \%$ of the maximal oxygen uptake ( $\mathrm{VO}_{2}$ max) as compared to 75,40 , and $25 \%$ and rest) negatively affected performance on coincidence anticipation which task measures skilled tuming performance. These studies supported the conclusion of Fleury, Bard, and Carriere (1981) that fatigue mainly affects complex cognitive functioning that requires a great deal of the resources of the central nervous system. However, Paas and Adam (1991) noted an unexpected beneficial effect of a substantial change in workload (cycling at $75-85 \%$ of the $\mathrm{VO}_{2} \mathrm{max}$ ) on a decisional task, while no effect was observed on a simpler perceptual task. It is thus unclear whether and how physical fatigue may affect simple and complex cognitive processing.

A possible flaw of former studies is the use of exercise of short duration $(<15 \mathrm{~min}$ ) to induce fatigue. Thus, in the present study, subjects were tested before and immediately after prolonged $( \pm 60 \mathrm{~min}$.) endurance exercise. Endurance tests are thought to induce exhaustion or physical fatigue (Jeukendrup, Saris, Brouns, \& Kester, 1996) which is then implicated in the decline of performance that occurs on any prolonged or repeated task (Kennedy, 1988). Subjects were not tested during exercise since earlier McMorris and Keen (1994) and Isaacs and Pohlman (1991) hypothesized that divided attentional mechanisms rather than actual effects of fatigue caused the decreased performance which was seen during cycling on cognitive tasks. With higher arousal, subjects may focus rather on internal perceptions of discomfort (an hypothesis first described by Nideffer, 1979) than focus on cognitive tasks. The present study is similar to the study by Fleury, et al. (1981) in that farigue is defined as the consequence of a physical workload on subsequent psychological performance. If latigue affects the functioning of the central nervous system, fatiguing exercise should especially affect complex, decisional, cognitive tasks (Easterbrook, 1959; Gutin, 1973; Kennedy, 1988; Fleury, et al., 1981). Because subjects can compensate for a lack of energy by investing additional effort on a psychological task (Zijlstra \& Meijman, 1989), the effort invested in task performance was taken into account as a modulating variable. Simple measures of speed (tapping and simple reaction time) were also taken into account. Performance on these tasks often improves after or during exercise, possibly due to enhanced activation (Easterbrook, 1959; Gutin, 1973; Salmela \& Ndoye, 1986). Heart rate was measured as an indication of the intensity of performance and arousal or activation at the time of testing. We tested the hypotheses that (1) subjects would perform faster on simple tasks after an endurance test than before the test 
and (2) subjects would perform worse on complex cognitive tasks after an endurance test.

\section{METHOD}

Subjects

Fifteen healthy male triathletes and competitive cyclists participated. The subjects had enrolled in a validation study of endurance performance (Jeukendrup, et al., 1996). They trained on a regular basis ( $22 \mathrm{hr} / \mathrm{day}$ and $\geq 4$ times/week). The mean age of the subjects was 24.9 yr. $(S D=7.9$; range $=$ 18 to 42), their mean weight was $73.5 \mathrm{~kg}(S D=6.5)$, and their mean height was $183 \mathrm{~cm}(S D=4.5)$.

\section{Design and Procedure}

The experiment was conducted according to a single factor repeated. measures design. The factor "Level of exercise" consisted of three levels (preexercise, postexercise, baseline). Subjects came to the laboratory three times at 7 -day intervals. The first visit was intended to familiarize the subjects with the tests and procedures. On the second visit, heart rate and cognitive tests were measured before and after the endurance rest. Baseline measurements were taken on the third visit.

One week before the experiment, maximal workload was attained on a bicycle ergometer during an incremental exercise test until exhaustion. After a warm-up period of $5 \mathrm{~min}$. at $100 \mathrm{~W}$, the workload was increased every 2.5 min. until heart rate reached $160 \mathrm{beats} / \mathrm{min}$. Then workload was increased with $25 \mathrm{~W}$ every $2.5 \mathrm{~min}$. until the pedaling rate dropped below $60 \mathrm{rpm}$. The maximal work capacity ( $\mathrm{W}$ ( $\mathrm{max}$ ) was determined by the following formula: Wmax $=$ Wout $+(t / 150) \cdot 25$, where Wout is the workload of the last completed step, $t$ is the time in the final step. Mean maximal workload of the subjects was $385 \mathrm{~W}$ (33), indicating that subjects were well-trained.

The exercise consisted of a short warm-up ( $5 \mathrm{~min} .100 \mathrm{~W}$ ) followed by a simulated time trial. In this time trial subjects were asked to perform a certain amount of work (equal to about 1 hour of cycling) as fast as possible. This total amount of work was based on the maximal workload (Wmax) according to the formula:

$$
\text { Total amount of work }=0.75 \cdot \text { Whax } \cdot 3600 \text {. }
$$

The ergometer was set in the linear mode according to the formula

$$
W=L \cdot(\mathrm{RPM})^{2}
$$

in which RPM is the pedaling rate and $L$ is a linear factor. This factor was chosen in a way which would cause a pedaling rate of 90 RPM at $70 \%$ of the maximal work capacity. In other words, the linear factor was dependent 
on a subject's maximal work capacity. This would mean that $75 \%$ of the maximal work capacity could be achieved at abour 100 RPM which appeared to be the preferential pedaling rate of most of the cyclists. This type of exercise can be classified as 'maximal' or 'exhaustive' and subjects usually report maximal values on Ratings of Perceived Exertion (Salmela \& Ndoye, 1986).

\section{Apparatus}

During the experiment, the subjects cycled on a Lode electronically braked ergometer (Lode Excaliber Sport ${ }^{\mathrm{R}}$, Lode BV, Groningen, The Netherlands). Heart rate was measured electronically using a Dinamap" (Critikon, Type 8100 ) before and immediately after exercise.

Psychomotor and Cognitive Tasks

Subjects completed a short test battery (15 min.) which included complex cognitive and psychomotor tests. The following tests were included.

The Stroop Color-Word test_-This is a well-known test for the ease of shifing perceptual sets to conform to changing task requirements (Lezak, 1983). The test consists typically of three subtests (Bohnen, Jolles, \& Twijnstra, 1992). In Subtest I, 10 rows by 10 columns of color names (red, blue, green, and yellow) are printed in black on white cardboard. In Subtest II, the same number of correspondingly colored patches are printed, whereas Subtest III contains a number of color names, printed in incongruously colored ink. For instance, the word "red" can be printed in green. The protocol for administering the test in this study was as follows. For Subtest I ("Color Word Reading"), the subject was requested to "read the collor names row by row, as fast as you can, without making any mistakes." The time needed to complete the whole card was recorded with a stopwatch. For the second subtest (Color Naming") the instruction was to "name the colored patches." The third subtest ("Color-Word Interference) involved naming the color of the ink in which the names of colors were printed without paying attention to the word itself. For each subtest the time taken to finish the card was recorded. In this study the short version was used. The short version stops after 40 stimuli (whereas the whole test contains 100 stimuli). The correlation between the abridged version and the original version is remarkably high (Pearson $r=.93, p<.001$ on average for all cards) (Klein, Ponds, Houx, \& Jolles, in press).

The Choice Reaction Thme tert.-The subjects pressed one button and were asked to press one of five other buttons located equidistant from the hold button when they onset. This yielded reaction times in three subsequent conditions of increasing task complexty. The response set consisted of pressing only one bution that lit up (simple RT), pressing one of three buttons that lit up (3-choice RT), or pressing the button to the right of the 
lighted button (incompatible 3-choice RT) as quickly as possible. Hence, on these three subtasks, two task factors are systematically varied within subjects: the number of response alternatives, and the comparibility of the stimulus and the required response (Houx, Vreeling, \& Jolles, 1991 ).

The Finger Tapping Test,-Finger-tapping speed is one of the more simple aspects of psychomotor performance. The time elapsed between two single taps was registered with an IBM (Type 486) compatible computer at millisecond accuracy. In this experiment the number of taps per second (on a response button on a panel connected to the computer), using the preferred hand, was used as a dependent variable (Brand \& Jolles, 1988).

Effort.-Effort was measured using the Rating Scale ('BeoordelingsSchaal') for subjectively experienced Mental Effort ('Mentale Inspanning'). Apart from a global indication of the psychophysiological state of the subjects (fatigue), the amount of effort can also be seen as an indicator of the "cost" of performing a task. This scale was constructed by using the "magnitude-estimation method' with several different population samples (bus drivers and students) and different rating modalities to estimate the scale values of the nine adjectives (not at all exhausting, hardly exhausting, slightly exhausting to extremely exhausting) (Zijlstra \& Meijman, 1989). The data from the original $15-\mathrm{cm}$ visual analog scale were transformed to percentages.

Statistical Analyses

The "Level of exercise" effect was tested for each task according to a repeated-measures design with three levels: low (preexercise), high (postexercise), and low (baseline). The main effect of "Level of exercise" was evaluated in conjunction with task factors in repeated-measures, within-subjects analysis of variance. The task factors were number of response alternatives (2 levels: 1 or 3 responses), and S-R Compatibility ( 2 levels: Compatible, Incompatible) in the Motor Choice Reaction Task, and Color Naming (2 levels: Words, Colors), and Color-Word Interference (2 levels: Response Conflict, No Response Conflict) in the Stroop task. Post hoc paired $t$ tests were used to assess the differences between the pairs of experimental conditions. Probabilities of .05 or less are reported as significant. Nonsignificant probabilities are reported when they are between .05 and .10 . All analyses were performed with SPSS 4.0 on an Apple MacIntosh computer.

\section{Results}

Heart rate was significantly different over conditions as multivariate analyses showed $\left(F_{2,13}=36.65, p<.001\right)$. Heart rate was significantly lower before exercise $\left(t_{14}=-8.72, p<.001\right)$ and baseline $\left(t_{14}=8.71, p<.001\right)$ relative to that after exercise (see Table 1).

The subjects took significantly longer to complete the Stroop subtask Color Naming than they did the subtask Color Word Reading. Multivariate 
analysis indicated a main effect of stimulus type (Words, Colors) ( $F_{\text {a: }}=$ $57.88, p<.001)$. Also, a main effect of the factor "Level of exercise" $\left(F_{2.13}=\right.$ $15.97, p<.001$ ) and a significant interaction between stimulus type and "Level of exercise" were detected $\left(F_{2,13}=5.78, p=.02\right)$. Post boc paired $t$ tests berween conditions showed learning effects on both cards. Time needed to perform Color Word Reading was significantly longer before than after exercise $\left(t_{14}=2.36, p<.05\right)$ and at baseline $\left(t_{14}=2.74, p<.05\right)$ and equal after exercise to that at baseline $\left(t_{14}=-.48, n s\right)$, signifying a bottom effect. On Color Naming the learning effect was even more dearly shown, since significantly more time was needed to perform this task before exercise than afterwards $\left(t_{14}=\right.$ $3.17, p<.01)$ and baseline $\left(t_{14}=4.95, p<.001\right)$ and after exercise relative to baseline $\left(t_{1.5}=2.79, p=.01\right)$. Response time on the Color-Word Interference subtask was significantly longer than that on the Color Naming subtask since multivariate analysis showed that a main effect of stimulus type (Response Conflict, No Response Conflict) was significant $\left(F_{6.14}=52.79, p<\right.$ $.001)$. Also, the "Level of exercise" effect $\left(F_{2,13}=7.14, p<.01\right)$ and the interaction of stimulus type and "Level of exercise" were significant $\left(F_{2,13}=\right.$ $10.34, p<.01)$. As can be seen in Table 1 , exercise clearly affected ColorWord Interference. This was confirmed with post boc paired t tests. Time needed to perform the Color-Word Interference was longer before exercise than afterwards $\left(t_{14}=3.42, p<.005\right)$ but equal to baseline $\left(t_{14}=1.58, p>.10\right)$. The baseline performance was significantly longer than the time needed to perform the task after exercise $\left(t_{14}=-3.56, p<.005\right)$.

On the Motor Choice Reaction Time test, Choice RTs were longer than simple RTs. Multivariate analysis yielded a main effect of the number of response alternatives (2 levels: 1 or 3 responses) $\left(F_{1,13}=113.36, p<.001\right.$ ). A main effect of the factor "Level of exercise" was seen on multivariate analysis $\left(F_{2,12}=6.28, p=.01\right)$. Exercise did not affect the relation between the number of response alternatives and $\mathrm{RT}$, since no interaction was seen between the number of response alternatives and "Level of exercise" ( $F_{2,12}=$ .71 , ns). Post boc paired t tests indicated that a lower mean response time on the simple reaction time task was seen after relative to before exercise $t_{1: 4}=$ $1.99, p=.07)$. No difference was seen between the preexercise condition and baseline $\left(t_{13}{ }^{2}=-17\right.$, ns) but response time after exercise was significantly lower than at baseline $\left(t_{13}=-2.81, p=.01\right)$. Choice reaction time showed no effect of condition; response times were equal across conditions. Incompatible RTs took longer than compatible RT's. Multivariate analysis indicated a main effect of "S-R Compatibility" (2 levels: Compatible, Incompatible) $\left(F_{1,13}=57.32, p<.01\right)$. "Level of exercise" was nonsignificant $\left(F_{2.12}=2.87, p=\right.$ 
TABLE 1

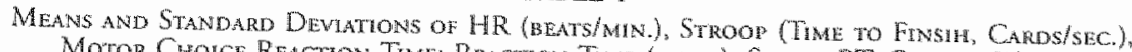

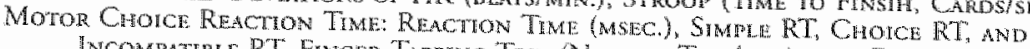

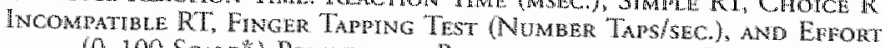

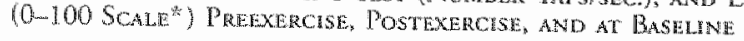

\begin{tabular}{|c|c|c|c|c|c|c|}
\hline \multirow[t]{2}{*}{ Task } & \multicolumn{2}{|c|}{ Picexencise } & \multicolumn{2}{|c|}{ Postexercise } & \multicolumn{2}{|c|}{ Baseline } \\
\hline & M & $S D$ & $M$ & $S D$ & $M$ & $S D$ \\
\hline Heart Rate, bpm & 63.1 & 15.3 & 103.0 & 145 & 65.5 & 14.6 \\
\hline \multicolumn{7}{|l|}{ Stroop Test } \\
\hline Color Reading & 13.3 & 2.0 & 12.6 & 2.0 & 12.7 & 21 \\
\hline Color Naming & 17.6 & 3.5 & 16.5 & 2.6 & 15.5 & 2.5 \\
\hline Color-Word Interference & 23.3 & 6.3 & 20.8 & 4.4 & 22.2 & 4.6 \\
\hline Motor Choice-Simple RT & 378 & 37 & 369 & 48 & 379 & 51 \\
\hline Choice Ret & 429 & 53 & 417 & 39 & 420 & 43 \\
\hline Incompanible RT & 494 & 61 & 485 & 65 & 488 & 64 \\
\hline Finger-tapping Test & 7.0 & .8 & 6.9 & .6 & 7.0 & .8 \\
\hline Effort Scone & 53.1 & 3.9 & 54.5 & 4.8 & 51.2 & 4.3 \\
\hline
\end{tabular}

.09), indicating no effect of exercise in the Incompatible task. The interaction between "S-R Comparibility" and "Level of exercise" was also nor significant $\left(F_{2,12}=.05, \mathrm{~ns}\right)$. On the incompatible subtask, lower response time after exercise than before $\left.v_{14}=1.91, p=.08\right)$ was not significant and no differences were seen when pre- and postexercise condirions were compared with baseline conditions $(p>50)$. The average number of taps per second was 6.97 and did not differ significantly between conditions $\left(F_{2,4}=.18\right.$, ns $)$. The average subjectively experienced effort was 52.90 on a scale of 100 and did not significantly differ between conditions $\left(F_{2.13}=.17\right.$, ns $)$.

\section{Discussion}

The results of the experiment support the first hypothesis, namely, that exercise has a positive effect on performance speed in simple tasks. Simple RTs were significanty lower after fatiguing exercise than at baseline. However, simple manual motor speed which is mainly limited by peripheral factors (Tapping) was not influenced at all by exercise of high intensity. Further, the results did not support the second hypothesis, that endurance ex. ercise would have a general detrimental effect on complex cognitive functions. In fact, the opposite was found. For instance, the RT for the most complex task that required the inhibition of a learned response, the ColorWord Interference subtask of the Stroop test, was decreased by endurance exercise. Important is that the subjectively experienced effort was not increased, and no more errors were made with the higher speed of performance.

The findings seem to indicate that there is no clear-cut relation between physical fatigue immediately after endurance exercise and mental fatigue as 
was suggested by Tatakuwa (1971). However, it is possible that the subjects were not thoroughly fatigued, and it may be worthwhile to study farigue after an extended period of endurance exercise.

The enhanced performance on psychomotor and cognitive tasks can be explained in the following fashion. Gutin (1973) proposed that various amounts of activation differently affect certain types of mental tasks. Low activation is best for performance of tasks which require a great deal of information processing. Low activation is reflected by a slight increase in heart rate during and after exercise (90 to $120 \mathrm{bpm}$ ). Higher activation, provoked by exercise of long duration ( $> \pm 15 \mathrm{~min}$., inducing a heart rate of more than $160 \mathrm{bpm}$ ), should diminish performance on tasks that require a great deal of information processing. In the study of Isaacs and Pohlman (1991) in which exercise had a negative effect on complex tasks, heart rate was 150 to $175 \mathrm{bpm}$. Although we found that exercise of longer duration at heart rates of 160 to $180 \mathrm{bpm}$ had a beneficial effect on performance of complex cognitive tasks, these effects were seen after exercise, which was contrary to Gutin's expectations. However, during the actual testing activation was still sufficiently enhanced (heart rate $90-120 \mathrm{bpm}$ ) to lead to an improved performance consistent with the first hypothesis. Thus, at the time of psychomotor and cognitive testing, the subjects were still in a highly aroused state. Hence, the enhanced performance on the tasks after exercise might reflect a generally increased activation of the central nervous system. The absence of this effect, as reflected by the means on the Tapping task, could reflect a ceiling effect.

The finding of a significant interaction between exercise and the results of the most complex task, Stroop Color-Word Interference, is interesting. This effect may be comparable to that found by Paas and Adam (1991) who also reported an unexpected beneficial effect on a clecisional task during a substantial change in workload (cycling at $75-85 \%$ of the $\mathrm{VO}_{2}$ max). The authors concluded that subjects in their study apparently had decided to invest more processing capacity or resoutces into the more complex (decision) task. Similar findings were reported by Adam, et al. (in press). Although effort in our study was not elevated after exercise, it is possible that subjective scales of effort are not reliable or valid indicators of the actual effort invested. An (un) conscious decision made by the subjects actually to invest more effort in certain tasks is infuenced by motivation and probably the effects of expectancy. Tomporowski and Ellis (1986) previously suggested that many studies may have been confounded by expectancy effects. The expectancy of the participants influences performance through motivational variables. Hence, the subjects may have compensared to overcome the possible effects of fatigue. This compensation effect is especially seen in highly trained subjects and is not mediated by fitness but rather, as mentioned by Tomporowski 
and Ellis (1986), by the expectancy that exercise has a beneficial effect in general. Subjects who do not often engage in exercise of high intensity have a negative expectancy about the effect of exercise on cognition. For instance, Delignières, Brisswalter, and Legros (1994) showed that experts exerted additional effort to overcome the effects of fatigue when challenged. Their performance increased as exertion increased (cycling at 20,40,60, and $80 \%$ of maximal aerobic power). Nonexperts of similar fitness showed a decrease in performance on their 2 -and 4-choice $\mathrm{RT}$ task. The error rate in both groups remained stable.

It is thus unclear whether the effects seen in the present study are mediated by the effects of activation or expectancy; however, it is clear that expectancy variables and valid measures of effort should be taken into account in studies into the effects of fatigue. Preferably, expectancy should be controlled while effort is measured in an experimental design to study the actual relations among fatigue, expectancy, and effort.

\section{REFERENCES}

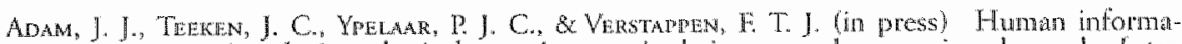
tion processing during physical exercise: manipulating mental processing demands. Water national jownd of Sport Pyohology.

BARD, C. E. Fleukr, M. (1987) Influence of imposed metabolic fatigue on visuall capacity com. ponents. Perceptut and Motor Skilks, 47, 1283-1287.

BRAND, N., \& Jolurs, J. (1988) NEUROPSYCH: computer-assisted neuropsychological assessment. In F. J. Maarse, L. H. M. Mulder, W. P. B. Sjouw, \& A. E. Akkerman (Eds.),

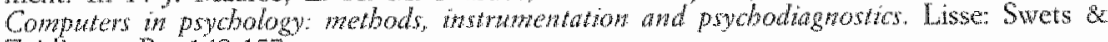
Zeitlinger. Pp. 149.157 .

Bonnen, N., Jolles, ]. \& Twinstra, A. (1992) Moditication of the Stroop Color Wond Test improwes differences between patients with mild head-injuly and matched controls. The Clinical Netrologist, 6, 178.184.

Côté, J., Salmeta, I. H. \& Papathanasopoulu, K. 19. (1992) Effects of progressive exercise on attentional focus. Percepkat and Motor $S k i l l s, 75,351-354$.

Delignieres, D., Brisswalmer, J., \& Legros, P. (1994) Influence of physical exercise on choice reaction time in sponts experts: the mediating role of resoure allocation. Jownal of Human Movertand Sindies, 27, 173-188.

EAsternarook, J. A. (1959) The effects of emotion on cue utilization and the organization of behavion. Pryologucal Rewaw, 66, 183-281.

Flefury, M., Bard, C., Carritre, L. (1981) Elfecis of physical or perceptual work loads on a coincidence/anticipation task. Percephat and Moton' Skills, 53,843-850.

Fuetry, M., Bawo, C. Jorin, J., \& Carrers, L. (1981) Influence of difterent types of pinysicul fatigue on a visual detection task. Perteptat and Moror Sisills, 53,723,730.

Gutr, B. (1973) Exercise-induced activation and human perfomance: a review. Reseroh Quarterly, 44,256268 .

HANCOCK, S., \& MeNAUGHTON, L. 1986 ) Effects of fatigue on ability to process wisual infor. mation by experienced orienteers. Perceptal and Motor $\$ 2$ ills, $62,491-498$.

Houx, P. I., VReELANG, F. W., \& Jonles, J. (1991) Age-associated cognitive dedine is related to biological literevents. In K Iqbal, D. R C. McLanghin, B. Winblad, \& H M. Wusniew

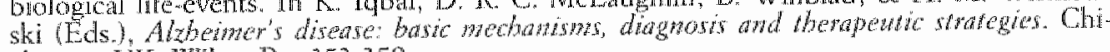
chester, UK. Wiley. Pp. $353-35 \%$

IsaACs, L. D. \&. Pohlmak, R. L. (1991) Effects of exercise intensity on an accompanying timing task Jownal of Human Mowemant Studies, 20, 123-131.

JEUkENDRUP, A. SARL, W. H. M. BkOUnS, F, \& Kester. A. D. M. (1996) A new validated endurance performance test. Mediche and Sckence in Spots and Exercise, $28,266-270$. 
KenNeDr, H. G. (1988) Fangue and tangability. Britsh Jourat of Prychidry, 153, 1.5.

Kumm, Ka, Ponds, R. W. H. M, Houx, P. J. \& Jolles, J. (in press) Effect of test duration on age-ratated diferences in Stroop Tnterherence. Jow of Climal and Experimentat Netropryobology, 19

Lezak. M. D. 119831 Nenopsycbological assessnents. (2nd ed.) New York: Oxford Unwer. Mressin

McMorrs, T., \& Ken, P. (1994) Effect of exercise on simple reaction times of recreational athletes. Perceptuat and Motor 5 kills, $78,23-130$.

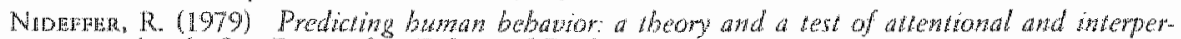
sonal syle. San Diego, CA: Enhanced Performance Assoc.

PAAS, $\mathbb{E}$, \& ADAM, $J$. (1991) Humam information processing during physical exercise. Ergonom ics, $34,1385-1397$.

SAlkELA, J. H., \& NDON, O. D. (1986) Cognitive distortions during progressive exercise. Pepcoptual and Moror Stills, $63,1067-1072$.

'TATrkUWA, K. (1971) Maintaining concentration (TAF) as a measure of mental stress. In $K$. Haghimoto, et al. (Eds.), Meshodology ith butas fatigze assersmewt. London: Taylor \& Firancis.

Tomporowstr, P. D., \& E.us, N. R. (1986) Effects of exercise on cognime processes: a review. Prychological Balletin, $99,338.346$.

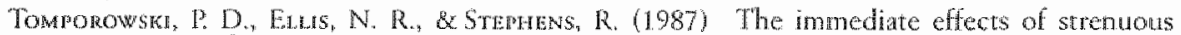
exercise on free recall memory. Ergopromics, $31,121-129$.

Zijustra, F, \& Mejman, T. (1989) Het meten van mentale inspaning met behulp wan een subjecticve methode. In T. Meiman (Ed.h, Mendale bolasting en werkestress eer arboidpsy. chologische benadering. Assen/Maastricht: Van Gorcum. Pp. $42-61$.

Accepted July 17, 1996 